Research Article

\title{
Efficacy of alternate day versus daily atorvastatin in reduction of low density lipoprotein cholesterol: a prospective, randomized, open labelled, parallel group study
}

\author{
Nishikant Nandlal Mankar*, Vijay Ramkrishna Zad, Monali Pradeep Vakharia
}

\begin{abstract}
Department of Pharmacology, Dr VMGMC, Solapur, Maharashtra, India

Received: 07 May 2016 Accepted: 08 June 2016

*Correspondence to: Dr. Nishikant Nandlal Mankar, Email: nishikantmankar@ gmail.com
\end{abstract}

Copyright: () the author(s), publisher and licensee Medip Academy. This is an openaccess article distributed under the terms of the Creative Commons Attribution NonCommercial License, which permits unrestricted noncommercial use, distribution, and reproduction in any medium, provided the original work is properly cited.

\begin{abstract}
Background: Cardiovascular disease (CVD) is the leading cause of death in India and worldwide. Hypercholesterolemia plays a pivotal role in atherogenesis which gave rise to universally accepted cholesterol diet-CVD hypothesis. Statins are the most potent and commonly used drugs for treating hypercholesterolemia. With atorvastatin, because of the long lasting active metabolites, half-life of HMG-CoA reductase inhibition reaches 20 to 30 hours. Thus, it is conceivable that alternate-day atorvastatin treatment might be effective in maintaining the lipid-lowering efficacy.

Methods: In this prospective, randomized, open labelled, parallel group study, 100 participants with serum low density cholesterol (LDL-C) level $100 \mathrm{mg} / \mathrm{dL}$ $190 \mathrm{mg} / \mathrm{dL}$ were recruited. Group A received $20 \mathrm{mg}$ atorvastatin on alternate day and group B received $20 \mathrm{mg}$ atorvastatin daily for 12 weeks. Follow up visits were scheduled at 6 and 12 weeks at which fasting serum LDL-C, serum TC, serum TG, serum HDL were estimated. Creatinine phosphokinase (CPK), aspartate transaminase (AST) and alanine transaminase (ALT) estimations were also done and participants were examined for occurrence of myalgia, jaundice or any other adverse effect.

Results: A statistically significant reduction in LDL-C, TC, and TG was seen in both the groups when compared to baseline. At 12 weeks, the LDL-C reduction in alternate day atorvastatin group was $34.63 \%$ whereas in daily atorvastatin group, it was 38.75.The reduction in levels of TC in alternate day and daily atorvastatin group was $24.64 \%$ and $25.85 \%$ respectively. Both the regimens were well tolerated.
\end{abstract}

Conclusions: The alternate-day dosing of atorvastatin is as efficacious and safe as that of its daily dosing.

Keywords: Atorvastatin, Alternate day, LDL-C, CVD

\section{INTRODUCTION}

Cardiovascular disease (CVD) is the leading cause of death in India and worldwide. Previously thought to affect primarily high-income countries, CVD now leads to more death and disability in low- and middle-income countries, such as India, with rates that are increasing disproportionately compared to high-income countries. ${ }^{1}$ The burden of cardiovascular mortality and disability is likely to drastically affect working-age adults in developing countries, leading to substantial reductions in productivity and resulting into economic losses. Thus, the growing CVD epidemic has a huge impact on social and macroeconomic status. ${ }^{2}$
Similarly, the prevalence of risk factors for CVD such as hyperlipidemia, hypertension, and obesity is also increasing. ${ }^{1}$ Majority of patients of CVD have hyperlipidemia as a major cause of increased atherogenic risk. ${ }^{3}$ Thus the pivotal role of hypercholesterolemia in atherogenesis gave rise to the almost universally accepted cholesterol diet-CHD hypothesis. ${ }^{4}$

So it is imperative to control the levels of blood lipids in order to reduce burden due to CVD. Cholesterol contributes to the elevated lipid levels and recognition of hypercholesterolemia as a risk factor has led to the development of drugs that reduce cholesterol levels. Although various drugs are available to treat hypercholesterolemia, 3-hydroxy-3-methylglutaryl- 
coenzyme A (HMG-CoA) reductase inhibitors or statins are the most potent and commonly used drugs for treating hypercholesterolemia. ${ }^{3}$ A number of trials have demonstrated the efficacy of statins in reducing fatal and nonfatal CVD events, strokes, and total mortality. ${ }^{5}$

Like other statins, atorvastatin is a competitive inhibitor of the HMG-CoA reductase, which is the rate-limiting step in cholesterol biosynthesis. Atorvastatin has been shown to reduce both total plasma and low density lipoprotein cholesterol (LDL-C) levels up to $45 \%$ and $60 \%$ respectively, in a dose-dependent manner when given to patients with hypercholesterolemia. Moreover, because of the long lasting active metabolites of atorvastatin, the half-life of HMG-CoA reductase inhibition reaches 20 to 30 hours, although the mean terminal elimination half-life $\left(t_{1 / 2}\right)$ of atorvastatin is 14 hours. Thus, it is conceivable that alternate-day treatment might be effective in maintaining the lipid-lowering efficacy of atorvastatin. ${ }^{6}$

Although statins are generally well tolerated and present a good safety profile, adverse effects such as muscle toxicity and effects on liver enzymes may occur in some patients. These adverse effects have been well documented in recent reviews, with muscle-related toxicity receiving the greatest attention. ${ }^{7}$ Such side effects make it difficult for some patients to tolerate a daily statin dose. Side effects such as myalgia appear to increase with medication dose, as well as with conditions that decrease plasma volume and the rate of drug metabolism, such as age and hypothyroidism, respectively. ${ }^{8}$

Today, statins are being used widely, having an important share in health expenses. In the light of aforementioned pharmacokinetics, atorvastatin treatment administered every other day can result in a significant decrease in health expenses, if its efficacy and safety is comparable to that of its daily dosing. The present study evaluates the efficacy and safety of alternate day administration of atorvastatin as compared to its daily administration in reduction of plasma LDL-C.

\section{METHODS}

This study was conducted in Shri Chhatrapati Shivaji Maharaj Sarvopchar Rugnalaya, Solapur, a tertiary care hospital attached to medical college. The study was approved by institutional ethics committee.

The patients coming to cardiovascular out-patient department (OPD), medicine OPD, diabetes OPD with LDL-C levels of $100 \mathrm{mg} / \mathrm{dL}$ to $190 \mathrm{mg} / \mathrm{dL}$ were enrolled in this prospective, randomized, open labelled, parallel group study. The exclusion criteria included active or chronic hepatic disease, coagulation disorder, impaired renal functions, hypersensitivity to the drug in the study, concurrent hypolipidemic medication, significant hypertriglyceridemia $(>400 \mathrm{mg} / \mathrm{dL})$, pregnancy or lactation, elevated serum aspartate transaminase (AST) and serum alanine transaminase $($ ALT) $\geq 3$ times the upper limit of normality; patients on immunosuppressant, azole antifungal agents, or warfarin and patients consuming $>7$ alcoholic drinks/week.

A written informed consent in a prescribed format was obtained from the participants. Baseline investigations included thorough physical examination i.e. height, weight, vital signs including medical history, and laboratory investigations like serum lipid profile, AST, ALT, serum creatine phosphokinase (CPK), complete hemogram, fasting blood glucose, serum urea and creatinine, 12 lead ECG and a chest X-ray PA view. Sample size was calculated with reference to the study conducted by Rifaie et al using mean and the respective standard deviation for LDL-C in two groups considering $5 \%$ level of significance and $99 \%$ confidence interval. ${ }^{9}$

A total 100 participants were enrolled for the study and were randomly assigned to two groups. Group A received atorvastatin $20 \mathrm{mg}$ alternate day orally whereas group B received atorvastatin $20 \mathrm{mg}$ daily orally for 12 weeks. No participant used any other lipid lowering agents like bile acid sequestrants, fibrates or niacin. Follow up visits were scheduled at 6 and 12 weeks. At each follow up, serum lipid profile, CPK, AST and ALT were estimated and patients were interviewed and examined for occurrence of myalgia, jaundice or any other adverse effect during the course of the study.

The efficacy assessment was done by observing changes in serum LDL-C, serum triglycerides, serum total cholesterol (TC), and serum high density lipoprotein cholesterol (HDL-C) levels from baseline to final assessment. The percentage of patients who achieved LDL-C $<100 \mathrm{mg} / \mathrm{dL}$ at the end of the study was also calculated. All analyses were conducted on fasting venous blood samples at Central Biochemistry Laboratory of the hospital. ${ }^{10-12}$

Quantitative data between the two treatment groups were analysed by unpaired t-test whereas within the group were analysed by using paired t-test. Comparison of nonparametric (qualitative) data between the study groups was done using Chi-square test. A 'p' value $<0.05$ was considered statistically significant. ${ }^{13}$

\section{RESULTS}

A total 100 patients were included in the study, of which 50 patients were allocated to daily atorvastatin group and 50 patients to alternate day atorvastatin group. During the study period one patient from alternate day atorvastatin group and two patients from daily atorvastatin group were lost to follow up and hence excluded from the analysis. Thus, 49 patients from alternate day atorvastatin group and 48 patients from daily atorvastatin group were considered for the analysis of data.

The baseline characteristics including age, sex, clinical condition, lipid profile were comparable in both the treatment groups (Table 1). 
Table 1: Baseline characteristics of patients.

\begin{tabular}{|llll|}
\hline Variables & $\begin{array}{l}\text { Alternate day } \\
\text { atorvastatin } \\
(\mathbf{2 0} \mathbf{~ m g}) \\
\mathbf{N = 4 9}\end{array}$ & $\begin{array}{l}\text { Daily } \\
\text { atorvastatin } \\
(\mathbf{2 0 ~} \mathbf{m g}) \mathbf{N}=\mathbf{4 8}\end{array}$ & p value \\
\hline Age (years) & $58.2 \pm 9.46$ & $60 \pm 8$ & $>0.05$ \\
\hline Gender & & & \\
\hline Male & 26 & 24 & $>0.05$ \\
Female & 23 & 24 & $>0.05$ \\
\hline Clinical condition & & \\
\hline CHD & 30 & 32 & $>0.05$ \\
HTN & 26 & 23 & $>0.05$ \\
DM & 9 & 10 & $>0.05$ \\
\hline Lipid profile (mg/dL) \# & & $>0.05$ \\
\hline LDL-C & $143.06 \pm 22.45$ & $147.08 \pm 19$ & $>0.05$ \\
\hline TC & $215.79 \pm 24.81$ & $211.91 \pm 23.74$ & $>0.05$ \\
\hline TG & $147.26 \pm 28.93$ & $152 \pm 25.30$ & $>0.05$ \\
\hline HDL-C & $41.91 \pm 3.31$ & $40.81 \pm 3.87$ & \\
\hline
\end{tabular}

Chi square test for qualitative data, \#Unpaired t test

Both the regimens reduced LDL-C, TC and TG significantly, and also caused a statistically significant increase in HDL-C compared to respective baseline. However, no statistically significant differences existed among the groups in regards to total or a percentage decrease in LDL-C, TC and TG both 6 weeks and 12 weeks (Table 2).

Table 2: Lipids (mg/dL) in both treatment groups.

\begin{tabular}{|llll|}
\hline & $\begin{array}{l}\text { Alternate Day } \\
\text { atorvastatin } \\
(\mathbf{2 0} \mathbf{~ m g})\end{array}$ & $\begin{array}{l}\text { Daily } \\
\text { atorvastatin } \\
(\mathbf{2 0} \mathbf{~ m g})\end{array}$ & p value \\
\hline 6 weeks & & & \\
\hline LDL-C & $106.85 \pm 13.10$ & $105.02 \pm 13.06$ & $>0.05$ \\
\hline TC & $172.95 \pm 15.62$ & $167.72 \pm 17.19$ & $>0.05$ \\
\hline TG & $126.26 \pm 23.28$ & $122.91 \pm 21.85$ & $>0.05$ \\
\hline HDL-C & $43.36 \pm 3.27$ & $42.81 \pm 4.02$ & $>0.05$ \\
\hline 12 weeks & & & \\
\hline LDL-C & $93.51 \pm 13.53$ & $90.08 \pm 10.83$ & $>0.05$ \\
\hline TC & $162.61 \pm 16.13$ & $157.12 \pm 14.93$ & $>0.05$ \\
\hline TG & $117 \pm 21.97$ & $113.27 \pm 21.92$ & $>0.05$ \\
\hline HDL-C & $45.22 \pm 3.28$ & $44.66 \pm 4.10$ & $>0.05$ \\
\hline
\end{tabular}

Figures are Mean \pm Standard Deviation.

The percentage reduction of LDL-C levels in alternate day atorvastatin group and in daily atorvastatin group at 12 weeks was $34.63 \%$ and $38.75 \%$ respectively. The percentage reduction in $\mathrm{TC}$ in alternate day atorvastatin group and in daily atorvastatin group at the end of the study was $24.64 \%$ and $25.85 \%$ respectively. At 12 weeks, $69.38 \%$ patients from alternate day atorvastatin group and $79.16 \%$ from daily atorvastatin group achieved the level of LDL-C $<100 \mathrm{mg} / \mathrm{dL}$.

The difference in the increase in HDL-C in the two groups at both the follow ups was not statistically significant.
Table 3: Incidence of adverse effects in the treatment groups.

\begin{tabular}{|lll|ll|}
\hline Adverse effects & $\begin{array}{l}\text { Alternate day } \\
\text { atorvastatin } \\
\text { (N=49) }\end{array}$ & $\begin{array}{l}\text { Daily } \\
\text { atorvastatin } \\
\text { (N=48) }\end{array}$ & \\
\hline $\begin{array}{l}\text { No. of } \\
\text { patients }\end{array}$ & $\%$ & $\begin{array}{l}\text { No. of } \\
\text { patients }\end{array}$ & $\%$ \\
\hline Nausea & 3 & $6 \%$ & 4 & $8 \%$ \\
\hline Headache & 1 & $2 \%$ & 2 & $4 \%$ \\
\hline Bodyache & 3 & $6 \%$ & 1 & $2 \%$ \\
\hline Abdominal pain & 2 & $4 \%$ & 1 & $2 \%$ \\
\hline
\end{tabular}

There was no occurrence of any serious adverse event in any patient during this study (Table 3). The adverse events were mild, hence did not require discontinuation of the study drug. There was no statistically significant difference in the incidence of the adverse effects in the two treatment groups $(\mathrm{p}>0.05)$. No musculoskeletal adverse effects like myalgia, rhabdomyolysis were encountered.

\section{DISCUSSION}

Patients enrolled in the study received either atorvastatin (20 mg) as alternate day or as daily therapy. In several studies such as Pramanik et al, Keles et al and Aghasadeghi et al which compared the efficacy and safety of alternate day atorvastatin therapy with that of daily atorvastatin, a dose of $20 \mathrm{mg}$ atorvastatin was used. ${ }^{14-16}$

The results of the present study indicate that the alternate day atorvastatin therapy is as effective and safe as its daily treatment in reduction of LDL-C. In both the groups, a significant reduction in LDL-C was seen but the difference between the two groups was not statistically significant, findings similar to those of Matalka et al, Pramanik et al and Keles et al. ${ }^{6,14,15}$

Regarding the percentage of the participants achieving LDL-C levels $<100 \mathrm{mg} / \mathrm{dL}$, both the groups were comparable. A similar finding was seen in Matalka et al study where $43 \%$ patients from alternate day atorvastatin group and $75 \%$ patients from daily atorvastatin group achieved LDL-C levels $<100 \mathrm{mg} / \mathrm{dL}(\mathrm{p}>0.05){ }^{6}$

The difference in the percentage reduction of TC between the two groups was not statistically significant. Similar findings had been reported by Pramanik et al where there was $27.14 \%$ reduction in TC with alternate day atorvastatin therapy and $29 \%$ with daily atorvastatin therapy. ${ }^{14}$ Juszczyk et al showed a greater percentage reduction in TC which might be because a higher dose (40 $\mathrm{mg}$ ) of atorvastatin, used in their study. ${ }^{8}$

The safety and tolerability elicited by both regimens in present study were consistent with the studies conducted by Keles et al, Jafari et al and Ghia et al. ${ }^{15,17,18}$ The adverse events were mild and none of the patients from either group discontinued the study drugs because of it. Patients were able to comply very well with the alternate day atorvastatin regimen. ${ }^{19}$ 
The study had a small sample size and was of short duration, thus the long term effects of alternate day atorvastatin therapy could not be evaluated. The patients included in the study had LDL-C levels less than 190 $\mathrm{mg} / \mathrm{dL}$. Thus, the results are not applicable to those who have higher LDL-C levels (more than $190 \mathrm{mg} / \mathrm{dL}$ ).

\section{CONCLUSION}

The alternate-day dosing of atorvastatin is comparable to its daily dosing with regard to efficacy and safety.

\section{ACKNOWLEDGEMENTS}

Authors would like to thanks to Department of biochemistry for analysing the fasting blood samples for lipid profile.

\section{Funding: No funding sources}

Conflict of interest: None declared

Ethical approval: The study was approved by the Institutional Ethics Committee (EC/15/2012)

\section{REFERENCES}

1. Huffman MD. Coronary Heart Disease India. Available at http://sancd.org/CHD\%20updated\%20fact\%20sheet $\% 2014 J u l y 2011 \% 20$ PDF. Accessed on 3 November 2013.

2. Leeder S, Raymond S, Greenberg H, Liu H, Esson K. A race against time the challenge of cardiovascular disease in developing economies. Available at http://earth.columbia.edu/news/2004/images/raceagai nsttime_FINAL051104.pdf. Accessed on 3 November 2013.

3. Bersot TP. Drug therapy for hypercholesterolemia and dyslipidemia. Brunton LL, Chabner BA, Knollmann BC, Editors. Goodman and Gilman's The Pharmacological Basis of Therapeutics. $12^{\text {th }}$ edition. McGraw Hill, New York. 2011;877-908.

4. Grundy SM, Balady GJ, Criqui MH, Fletcher G, Greenland P, Hiratzka LF, et al. Primary prevention of coronary heart disease: guidance from Framingham: a statement for healthcare professionals from the AHA task force on risk reduction. American Heart Association. Circulation. 1998;97(18):1876-87.

5. Law MR, Wald NJ, Rudnicka AR. Quantifying effect of statins on low density lipoprotein cholesterol, ischaemic heart disease, and stroke: systematic review and meta-analysis. BMJ. 2003;326(7404):1423.

6. Matalka MS, Ravnan MC, Deedwania PC. Is alternate daily dose of atorvastatin effective in treating patients with hyperlipidemia? The alternate day versus daily dosing of atorvastatin study (ADDAS). Am Heart J. 2002;144(4):674-7.

7. $\mathrm{Hu}$ M, Cheung BM, Tomlinson B. Safety of statins: an update. Ther Adv Drug Saf. 2012;3(3):133-44.

8. Juszczyk MA, Seip RL, Thompson PD. Decreasing LDL cholesterol and medication cost with everyother-day statin therapy. Prev Cardiol. 2005;8(4):197-9.

9. Rifaie O, Zahran A, Nammas W. Alternate-day versus daily atorvastatin in coronary artery disease: a randomized study. Anadolu Kardiyol Derg. 2012;12(2):90-6.

10. Roeschlau P, Bernt E, Gruber W. Enzymatic determination of serum cholesterol. Clin Chem Clin Biochem. 1974;12:226.

11. McGowan MW, Artiss JD, Strandbergh DR, Zak B. A peroxidise coupled method for the colorimetric determination of serum triglycerides. Clin Chem.1983;29:538-42.

12. Burstein M, Scholnick HR, Morfin R. Rapid method for the isolation of lipoproteins from human serum by precipitation with polyanions. J Lipid Res. 1970;11:583-90.

13. Lwanga SK, Lemeshow S. editors. Sample size determination in health studies. A practical manual. Genev, Switzerland: World Health Organisation; 1991.

14. Pramanik S, Das AK, Chakrabarty M, Bandyopadhyay SK, Ghosh M, Dalai CK. Efficacy of alternate-day versus everyday dosing of atorvastatin. Indian J Pharmacol. 2012;44(3):362-5.

15. Keleş T, AkarBayram N, Kayhan T, Canbay A, Sahin D, Durmaz T, et al. The comparison of the effects of standard $20 \mathrm{mg}$ atorvastatin daily and $20 \mathrm{mg}$ atorvastatin every other day on serum LDLcholesterol and high sensitive C-reactive protein levels. Anadolu Kardiyol Derg. 2008;8(6):407-12.

16. Aghasadeghi K, Zare D. Efficacy of alternate day dosing of atorvastatin. Cent Eur J Med. 2008;3(2):163-6.

17. Jafari M, Ebrahimi R, Ahmadi-Kashani M, Balian H, Bashir M. Efficacy of alternate-day dosing versus daily dosing of atorvastatin. J Cardiovasc Pharmacol Ther. 2003;8(2):123-6.

18. Ghia CJ, Panda AS, Khobragade LR, Jha RK, Rambhad GS. Alternate day versus once daily atorvastatin for primary prevention of CHD in naïve patients of dyslipidemia. J Clin Diagn Res. 2014;8(3):27-31.

19. Piamsomboon C, Laothavorn P, Saguanwong S, Chatlaong B, Nasawadi C, Tanprasert P, et al. Efficacy and safety of atorvastatin $10 \mathrm{mg}$ every other day in hypercholesterolemia. J Med Assoc Thai. 2002;85(3):297-300.

Cite this article as: Mankar NN, Zad VR, Vakharia MP. Efficacy of alternate day versus daily atorvastatin in reduction of low density lipoprotein cholesterol: a prospective, randomized, open labelled, parallel group study. Int J Basic Clin Pharmacol 2016;5:1421-4. 